\title{
LINGUISTIC IDEOLOGY AND PRAXIS IN U.S. LAW SCHOOL CLASSROOMS
}

\author{
Elizabeth Mertz ${ }^{1}$
}

This paper explores the relationship between linguistic ideology and praxis through an examination of the language of U.S. law school classrooms. These classrooms afford an exciting opportunity for examining the socially powerful role of linguistic ideology as it intersects with and regiments linguistic practice. The language of professional socialization is at once a key part of the process whereby social identities are forged and changed, and an expression of the epistemologies of professional cultures that have important connections with the power structures of our society.

Legal socialization is particularly intriguing because legal institutions serve a special translating function in Western society. When rendering diverse realms of cultural experience in a common language, legal institutions use language as an important and integral part of a socially transformative process. Thus the act of translation $^{2}$ to legal language is one in which linguistic and social regimentation mesh - and law school classrooms are accordingly heavily focused upon the role of language in social process, predictably rich in linguistic ideologies.

Bourdieu and Passeron (1977) have described the educational process as one in which a new relation to language and culture is transmitted, in an apparently autonomous institutional setting that nonetheless constantly contributes to the reproduction and legitimization of the established social order. Similarly, anthropologists and sociolinguists working in classroom settings have frequently found in the language of the classroom a powerful orienting social practice (Anyon 1981; Collins 1986; Gee 1985; Heath 1977, 1983; Mehan n.d.; Philips 1972). Hidden behind the apparent content of a lesson may be a deeper message about how the world operates, about what kind of knowledge counts, about who may speak and how to

\footnotetext{
${ }^{1}$ I would like to thank the editors of this issue, Paul Kroskrity, Bambi Schieffelin, and Kathryn Woolard, for helpful comments and suggestions. I also wish to acknowledge the assistance of the extremely talented and diligent group of research assistants who have worked on this project to date: Nancy Matthews, who is the Project Manager, Jacqueline Baum, Janina Fenigsen, Robert Moore, Nahum Chandler, Carolee Larsen, Kay Mohlman, Leah Feldman, Mindie Lazarus-Black, and Shepley Orr. The daunting task of transcription has been undertaken with energy and care by Diane Clay and Leah Feldman at the ABF, and by Zellah Coleman and her group. The project is funded by grants from the Spencer Foundation and from the American Bar Foundation.

2 James Boyd White (1990) uses essentially this notion of "translation", though there are differences between his approach to language and the anthropological linguistic approach drawn upon here (see Mertz 1992).
} 
proceed - a cultural worldview that is quietly conveyed through classroom language. Thus we can see broader social patterns and struggles played out and transformed in the smaller-scale dynamics of classroom education (see Wertsch 1985a, 1985b; see also suggestions in Bourdieu 1987 and Halliday 1982 that legal educational institutions play a role in the rationalization of the legal system).

The study I am currently conducting involves taping, coding, and transcribing classes in fifteen law schools across the country, as well as interviewing participants in those classrooms. As we are still in the process of collecting data, this initial analysis should be understood as somewhat tentative.

On the one hand, I would like to draw on work by Woolard $(1985,1989$ a, 1989 b), Irvine (1989), Brenneis (1984), Gal (1987, 1989), Hanks (1989, 1990) and Hill (1985), who suggest ways in which linguistic ideology is a crucial part of the social grounding of language use and structure (rather than, for instance, treating ideology as an autonomous "cultural" level of phenomena). On the other hand, in analyzing the intersection of linguistic ideology, use and structure, I build on the Silversteinian formulation referred to in Woolard's introduction, a view which has been elaborated by Silverstein and other contributors to a volume entitled Reflexive Language (Lucy forthcoming) - and by Bauman and Briggs (1990) in their article on "Poetics and performance." Here linguistic ideology is not merely a false frame that distorts our vision of "reality," but rather it is part and parcel of the linguistic structure and praxis that we study (see Mertz 1989, forthcoming). Ideologies of language emerge at the meta-level, where language signals reflexively about its own signalling. A linguistic ideology may be very explicit, as when speakers overtly discuss aspects of language use. Or linguistic ideology may appear more subtly, for example, as a set of meta-level structural linguistic features indicating what kind of speech is occurring (or ought to occur) (see Silverstein 1979, forthcoming). In either case, the ideology is a part of the structure and practice of speaking (or writing or signing), emergent in linguistic structure but not completely determinative of or identical with the linguistic praxis in process. Thus linguistic ideology can at the same time distort or misrepresent and yet shape and reflect linguistic practice. This approach to linguistic ideology allows us to examine the ways in which social power and change are implicated in language structure - often through this process of ideological reflection and refraction.

I want to focus in particular on Silverstein's notion of a dialectic between pragmatics and metapragmatics, one aspect of which is the way in which "explicit metapragmatic registers instantiated in metapragmatic discourse encapsulate ideologies of language use and play an obvious role in the institutionalization of discursive mechanisms of society" (Silverstein forthcoming). The ongoing pragmatics of discourse achieve coherence only through some kind of metapragmatic structuring, ${ }^{3}$ which construes that ongoing discourse as being a certain type of discursive event. Participants in the same event can of course construe it differently, and therein lies some of the potential for maneuvering and struggle over the construction of discourse in key institutional arenas. I take it, however, that if we are ever to move beyond idiosyncratic interpretations of individuals to a more social view of this regimenting process, we must focus on moments when this typification

${ }^{3}$ There is some affinity between this approach and Gumperz' (1982) notion of "contextualization cues." 
process becomes more generally shared and explicit, approaching what Silverstein (forthcoming) calls "non-cancellability" or "interactional non-deniability." Use of a register signalling participants that this indexing is an event of such-and-such a type plays on linguistic ideology, ${ }^{4}$ for only through some sort of ideological formulation about language do we have a notion of types of discourse or events. At the same time, construing discourse as being of a certain type also permits it to function socially. It is not that there is only one possible understanding of what is happening in the discourse at that point, but rather that ideological struggle over the social meaning of the discourse takes place against the backdrop of explicitly typifying (i.e. socially sedimented) metapragmatic registers. Thus alternative meta-level ideological formulations can provide avenues of resistance. ${ }^{5}$

If we draw this idea of linguistic ideology together with the work by Woolard and others on social foundations of language, we see that there is a point at which the institutionalization of language can be understood as at once at work constantly in the structuring of discourse and as dependent upon an ongoing process of ideological sedimentation of metapragmatic types. This is exciting because there are parts of this ideological process that are more accessible to conscious reflection (presumably, the sedimentation of types), and parts that are at a level that Bourdieu (1977) talks about as habitus - the habitual structuring of language pragmatics and metapragmatics. This would account for both the somewhat resistant or nontransparent reactions of language to conscious (ideologically motivated) attempts at change and yet the central character of ideological reflection in institutionalized language use.

An adequate view of this process at work in law school classrooms is necessarily very complex, and I can only cover a small part of it here. I would like to look first at several language exchanges between professors in interviews, and then note briefly a difference that seems to be emerging between classes in schools of differing status.

I would like to focus on several exchanges in which students are not conforming to the discourse format urged upon them by the professor. Note that in these classes the reigning mode of interaction is a highly stylized genre known as the "Socratic method," in which the professor addresses a series of questions to a single student. Each question supposedly builds upon the student's previous answer and draws the student closer to the response the professor is seeking. Although a frequently expressed classroom ideology is that there are "no right answers" to questions, it is clear that there are wrong answers, as indicated by everything from pitch and intonation of professors' responses to overtly negative assessments of previous answers. The exchange of questions and answers pushes students toward certainty, urging them to take definite positions that they must then defend. (It matters not whether the position taken is "right" or "wrong", for as one professor

\footnotetext{
${ }^{4}$ For example, "Class, please take your seats; we're beginning our lesson now," or "You jerk, you're going to get an argument from me on that," both of which attempt to impose a meta-level typification of the ongoing speech event (formal classroom speech, argument).

${ }^{5}$ As, for example, if a pacifist responded to the argumentative comment in note 4 by saying "I'm not going to fight with you about this," contesting the typification which the first speaker sought to impose.
} 
told me, frequently the "wrong" answers are more useful as teaching devices; they permit a building up of suspense as the professor gets more and more students to adopt the incorrect position - he then can "spring" the correct answer on them, a procedure which he feels will burn the correct answer more indelibly into their brains). It is therefore a violation of the metapragmatic rules to refuse to take a position - or to refuse to give reasons for a position that lend themselves to this kind of back-and-forth (and in particular, this generally includes references to affect or emotion as a basis for a position).

I began with an exchange between a male professor and female student. The student has voiced an objection to the fairness of a case result:

Student: The contract, the original contract itself had a provision in it for prices that change due to an advance in case of the rise in the wages which actually happened causing the forward contract to be so much more expensive. So, if we're looking at expectation damages then the point that, I mean, in his contract that he had he would have, his original contract that the coke in that would have been subject to rise as well, would it not?

Professor: I don't know. What's the relevance of that to

Student: ... well

Professor:

(silence)

...how we solve the problem?

Student: (rising intonation) It just bothers me. I ...

Class: (laughter)

Professor: What bothers you?

Student: (silence, smiles, looks down)

Professor: What bothers you, I take it, is the parties thought about the problem of labor and the increased price in labor. And you're suggesting this was something they recognized. Now, do you want to go from there to say, if they recognized that, there was a problem with the cost of the labor. If there was going to be a stunningly disturbed market they should have said something about it, is that what you want to say? If that's what you want to say, where does that lead you?

Student: (again, silence, looks down)

Note that at the end of the exchange, the professor essentially adopts the student's voice, using indirect speech ("you're suggesting this was something they recognized"). The student has refused to budge from her chosen register "It just bothers me" and is indexing that refusal with silence. And so the professor speaks for her, taking her place in the dialogue and, in the absence of any cooperation from her, imbuing her with the correct voice. His insistent continuation of the dialogue, even without help from his interlocutor, forces upon this segment of speech the metapragmatic interpretation he seeks to impose - that this instance of speaking is an event of this discourse type (Socratic dialogue with its accompanying metapragmatic rules). One key rule is that interlocutors keep talking, keep coming up with reasons and justifications for articulated and antagonistically defended positions ("Where does that lead you?"). Her silence is an indication of a competing interpretation; this 
chunk of speech was an exchange in which she wishes to express a felt dissatisfaction with a case outcome. The power differential between interlocutors is perhaps evidenced by the fact that the final interpretation goes to the professor; yet her strongly maintained, smiling silence is a resistence that is not ultimately overcome by him. The timing of the class' laughter, incidentally, reinforced the professor's signal that her response was inappropriate.

The technique of taking a student's place in the dialogue when the student does not respond as desired is used in many of the classrooms in the study. More rare, but a dramatic illustration of the general metapragmatic struggle at work here, are times when the professor dictates to the student which words to use, as in one exchange in which the professor, after rephrasing a question several times (and receiving the same, "incorrect" answer - "no") tells the student "Try yes." The student initially responds with silence. The professor repeats, rising intonation, added stress, "Say yes." "Yes," says the student at last. "Why?" the professor proceeds to attempt a continued dialogue. Note here that there is a movement from more implicit metapragmatic indicators that the students' answers are unsatisfactory to a breakthrough into very explicit regimentation when all else fails.

Here metapragmatic regimentation of the discourse over resistances is the mode of socializing students, molding them into new social identities (lawyers) by literally putting new voices into their mouths and at once thoughts into their heads. ${ }^{6}$ This regimentation occurs through multiple layers of language, from subtler typification of chunks of speech as legal argument to overt appropriation of interlocutors' voices where necessary.

At times the connection between putting new voices into students' mouths and reformulating their identities becomes quite explicit, as in the following exchange:

(2) Professor: Tell me. Why are you in law school, Ms. C? Why are you studying the law? Don't tell me to become a lawyer, I understand that.

Student: It interests me.

Professor: Because it interests you. What a quaint way to put it. Why aren't you in business school? Where every sensible person probably ought to be now.

Student: I'm thinking of changing right now.

Proffessor: A possibly wise move. But why didn't you go directly to business school?

[I omit several turns in which the student reiterates that law school interests her, and the professor repeats his question]

Student: To do something different.

Professor: What is it that's different about the law from business?

Student: It's not certain, it's ever-changing.

${ }^{6}$ The classroom process, according to a famous metapragmatic saying, teaches students to "think like lawyers." 
Professor: Well, it is that. It is ever-changing. Or is it just that you like variety? Come Ms. C, you're not that shallow a person. Let's be honest. Let's force you to say something maybe you don't really mean. Let's psychoanalyze you. You're in law school rather than business school because you find it at bottom more deeply satisfying or at least you thought you could, to study the law than go to business school. You are not some lucre-seeking monster who would go to business school. You may be right, however, to be a lucre seeking monster at the present time in history, but that's not what you are. There is deep emotional fulfillment that you are supposed to be getting from the law school. That's why you came here.

Here the student is actually put in the position of giving "incorrect" answers about her own inner thoughts and motivations, and the professor in supplying the "correct" answers not only imports for her a way of talking, but an entire persona and set of normative orientations.

A more subtle but powerful and pervasive version of this occurs when professors rephrase students' answers to questions, telling them what they "meant":

Professor: ...We can say that the gift was given as an inducement for that behavior, right, because the promise to refrain comes after the gift. That's what you mean when you say that a contract as opposed to the gift has its own [inaudible], right? "I'll give you the money, if you do what you say you will do." Right? "I'll give you the money, if you refrain." Not, "I'll give you the money," "Thanks, I'll refrain." Alright. That's what you mean when you say it's conditional.

The professor imputes a precise, legally-framed meaning to the student's words, telling her what she should have meant when using the technical term "conditional." As in the previous example, there is an ideological movement from words to thoughts in the professor's reformulation of the student's speech, a powerful metapragmatic reframing that teaches an approach to texts and language as it attempts to reshape identities and ways of thinking.

Professors differ in their rationales for using a Socratic discourse format (it imitates courtroom dialogue, it keeps the students engaged, it is efficient in large classrooms, it imitates the mental process of "thinking like a lawyer" that the class dialogue attempts to inculcate). Although I do not yet have enough variation to say this with certainty, it appears that professors in lower status law schools tend to use a different discourse style, with fewer focused Socratic exchanges, and more of a free-floating exchange involving multiple students. ${ }^{7}$ What is inteesting is the

${ }^{7}$ To date, I have collected data in 7 schools: 2 "top-15" schools, 2 "regional" schools, 2 "local" schools, and 1 "night" school. Although we are only part of the way through coding these schools, it appears thus far that the most intensive use of focused dialogues between professors and single students (as opposed to "unfocused" dialogues in which multiple students join in) occurs in the two "top-15" schools and the more elite of the two "regional" schools. Again, however, I stress that this 
apparent continuities in metapragmatic structuring beneath these rationales and pragmatic differences, continuities expressing a more subtle ideology about language that is perhaps part of the system to which students are being socialized, of the texts they are being trained to read, of the way of speaking that the professors urge upon them. That ideology is not so much about why a certain form of classroom speech is useful or desirable, but rather focuses on the transparency of metapragmatic form to social result. "Taking a position" as an interlocutor in a dialogue is a necessary part of gaining power for legal actors. This taking of a position is a role-playing, and it doesn't matter which role you play as long as you play one. Again and again professors play roles - they take the parts of their students, and of various characters in the case dramas as those dramas unfold in classroom speech. Again and again professors push students to take these roles themselves and play them with certainty. Indeterminacy, breakthroughs of genuine affect (indexing through tone and gesture a failure to play the role), silence - are gaps in the dialogue, or, worse, refusals to acquiesce in the ongoing metapragmatic structuring of discourse.

That structuring is a key ideological message of law school socialization. It prepares students for a legal world which constantly effects a translation of people into their roles (plaintiff, defendant) and actions into their legal categories (tort, breach of contract), in a system in which either of two opposing results are always possible (guilty, not guilty), and in which effectual and "correct" metapragmatic regimentation (in courts, in legal documents, in law office talk) yields powerful social results. A key presupposition of the legitimacy of those results in our society is the untying of the drama as legally translated from its usual social moorings, the putative objectivity of the story once told in the apparently dispassionate language of the law. As the people in the cases become "parties," strategic actors on either side of a legal argument, they are stripped of social position; their gender, race, class, occupational and other identities become secondary to their ability to argue that they met one or another aspect of a legal test (for example, the requirement that there be "consideration" for valid contracts to exist).

Social context enters only through the backdoor, as when the professor warns the students about the way that the "equities"9 of a situation can skew legal results (for example, if the legal requirement that there be "consideration" is not met, but

is a tentative preliminary finding.

${ }^{8}$ This is the case on several levels; the metapragmatic form of at-times forced dialogue is ideologically represented as transparent to the social result of a transformed social identity for the students (language form inculcating new forms of talking and, at the same time, professional identity), as we have seen in the examples. But metapragmatic form is also represented as transparent to the social results of cases that are won by speakers able to hold up their end of similar dialogues, able to take on and speak roles fluidly. At a still deeper level, metapragmatic form mirrors legal epistemology, which derives its legitimacy in part from an act of translation of social events and actors into their legal categories and roles; these categories and roles, like the legal texts reentextualized in new legal opinions, are always part of an oppositional discourse in which one of two opposing parties - and interpretations - will "win" (see Mertz n.d., 1990).

${ }^{9}$ The concept "equities," deserving of an entire article by itself, is an interesting residual category which includes any social contextual or emotional aspect of the situation not strictly relevant to the legal tests, but still apt to sway judges or juries concerned about "fair" results. 
the judge or jury finds that there is a contract because of sympathetic feelings toward an indigent plaintiff). Even then, these "equities" become one more tool in the strategic toolbox, just one more argument to use in an effort to win. This bracketing of social context is deemed to be a crucial way in which law achieves objectivity, and lawyers achieve dispassionate professional competence.

A main task of the first year of law school is understanding the legal categories and how to "use" them. ${ }^{10}$ A realistic assessment of the "equities," of the possible effects of social context and emotions, is a small part of this task, necessary to effective strategy. The more central lesson is one of translating people and events into legal categories, no longer concentrating on the history and politics of the situation, but inquiring only as to whether the events fit the prescribed legal tests ("Was there consideration?" "Was there an offer and acceptance?"). The institutionalized linguistic ideology teaches that professional distance is obtained through translation of people and events into legal categories, so that they can be used strategically in a struggle for the dominant interpretation. "Taking a position on either side," "playing either role," is a feature of the metapragmatic regimentation of discourse that takes that institutionalized ideology to the heart of the speaking that comprises the legal arena.

\section{References}

Anyon, Jean (1981) "Social class and school knowledge." Curriculum Inquiry 11: 3-42.

Bauman, R. and C. Briggs (1990) "Poetics and performance as critical perspectives on language and social life." Annual Reviews in Anthropology 19: 59-88.

Bourdieu, Pierre (1977) Outline of a theory of practice. Cambridge: Cambridge University Press.

Bourdieu, Pierre (1987) "The force of law: Toward a sociology of the juridical field." Hastings Law Journal 38: 201.248.

Bourdieu, Pierre and J.C. Passeron (1977) Reproduction in education, society, and culture. London: Sage.

Brenneis, Donald L. (1984) "Straight talk and sweet talk: Political discourse in an occasionally egalitarian community." In D. Brenneis \& F. Myers (eds.), Dangerous words: Language and politics in the Pacific. New York: New York University Press, p.69-84.

Collins, James (1986) "Differential treatment in reading instruction." In J. Cook-Gumperz (ed.), The social construction of literacy. Cambridge: Cambridge University Press, p.117-137.

Gal, Susan (1987) "Codeswitching and consciousness in the European periphery." American Ethnologist 14: 637-653.

Gal, Susan (1989a) "Language and political economy." Annual Reviews in Anthropology 18: 345-367.

${ }^{10} \mathrm{I}$ assert this based both upon how much class time is devoted to teaching this task, and upon comments by professors I have interviewed. 
Gee, James (1985) "The narrativization of experience in the oral style." Journal of Education 167: 9. 35 .

Gumperz, John (1982) Discourse strategies. Cambridge: Cambridge University Press.

Halliday, Terence (1982) "Legal education and the rationalization of law: A tale of two countries the United States and Australia." American Bar Foundation Working Paper \#8711.

Hanks, William (1990) Referential practice: Language and lived space among the Maya. Chicago: University of Chicago Press.

Hanks, William (1989) "Text and textuality." Annual Reviews in Anthropology 18: 95-127.

Heath, Shirley Brice (1981) "Toward an ethnohistory of writing in education." In M.F. Whiteman (ed.), Writing: The nature, development, and teaching of written communication. Hillsdale, N.J.: Lawrence Erlbaum, p.25-45.

Hill, Jane (1985) "The grammar of consciousness and the consciousness of grammar." American Ethnologist 12: 725-737.

Irvine, Judith (1989) "When talk isn't cheap: Language and political economy." American Ethnologist 16: $248-267$.

Lucy, John (ed.) (forthcoming) Reflexive language. Cambridge: Cambridge University Press.

Mehan, Hugh (n.d.) "The construction of an LD student: A case study in the politics of representation." Ms.

Mertz, Elizabeth (n.d.) "Recontextualization as socialization: Text and pragmatics in the law school classroom." In M. Silverstein \& G. Urban (eds.), Natural histories of discourse (in preparation).

Mertz, Elizabeth (forthcoming) "Learning what to ask." In J. Lucy (ed.), Reflexive language. Cambridge: Cambridge University Press.

Mertz, Elizabeth (1989) "Sociolinguistic creativity: Cape Breton Gaelic's linguistic 'tip'." In N. Dorian (ed.), Investigating obsolescence: Studies in language contraction and death. Cambridge: Cambridge University Press, p.355-367.

Mertz, Elizabeth (1990) "Consensus and dissent in U.S. legal opinions: Narrative control and social voices." Anthropological Linguistics 30: 369-394.

Mertz, Elizabeth (1992) "Creative acts of translation: James Boyd White's intellectual integration." Yale Joumal of Law and the Humanities 4: 165-185.

Philips, Susan (1972) "Participant structures and communicative competence." In C. Cazden, V.P. John \& D. Hymes (eds.), Functions of language in the classroom. New York: Teacher's College Press.

Silverstein, Michael (1979) "Language structure and linguistic ideology." In P. Clyne, W. Hanks \& C. Hofbauer (eds.), The elements: A parasession on linguistic units and levels. Chicago: Chicago Linguistic Society, p.193-247.

Silverstein, Michael (forthcoming) "Metapragmatic discourse and metapragmatic function." In J. Lucy (ed.), Reflexive language. Cambridge: Cambridge University Press. 
Wertsch, James (1985a) Culture, communication and cognition. Cambridge: Cambridge University Press.

Wertsch, James (1985b) Vygotsky and the social foundation of mind. Cambridge, MA: Harvard University Press.

White, James Boyd (1990) Justice as translation: An essay in cultural and legal criticism. Chicago: University of Chicago Press.

Woolard, Kathryn A. (1985) "Language variation and cultural hegemony: Toward an integration of sociolinguistic and social theory." American Ethnologist 12: 738-748.

Woolard, Kathryn A. (1989a) "Sentences in the language prison." American Ethnologist 16: 268-278.

Woolard, Kathryn A. (1989b) "Language convergence and language death as social processes." In N. Dorian (ed.), Investigating obsolescence: Studies in language contraction and death. Cambridge: Cambridge University Press, p.355-367. 